\title{
Towards a Science of Complex Systems
}

This special topic issue of ComPlexUs contains selected papers that were presented at ECCS'05, the European Conference on Complex Systems, that took place at the Cité Internationale Universitaire de Paris, November 14-18, 2005.

Complex systems, as networks of interactive entities, are studied through a rapidly increasing mass of data in all domains. At the same time, these domains share a lot of new and fundamental theoretical questions. This situation is especially favourable for developing the new science of complex systems in an interdisciplinary way. The ECCS'05 is a step towards this new science.

There are two kinds of interdisciplinarity within complex systems. The first kind begins with a particular complex system and addresses a variety of questions com- ing from its particular domain and points of view. The second kind addresses issues that are fundamental to complex systems in general.

The first kind leads to domain-specific interdisciplinary fields such as cognitive science. The new science of complex systems belongs to the second kind of interdisciplinarity. It starts from fundamental open questions relevant to many domains, and searches for methods to deal with them.

These two kinds of interdisciplinarity are complementary and interdependent: any advance in one is valuable for the other. The science of complex systems will develop through a constantly renewed process of reconstructing data from models with a permanent interaction between the two kinds of interdisciplinarity. The reconstruction of the dynamics of complex systems presents a major challenge to modern science but it is becoming increasingly accessible through an accumulating mass of data, combined with the increasing power of computers, leading to theoretical advances in understanding.

This conference followed the one organized in Torino (Italy) in December 2004 with support from the coordination actions EXYSTENCE and ONCE-CS, funded by the Future and Emerging Technologies Unit of the European Commission. ECCS'05 benefited from the same support and was the first conference in an annual series organized by the new European Complex System Society (ECSS) and its Conference Steering Committee.

Our special thanks go to the staff at CIUP for preparing the ground for this conference. We would also like to thank the sponsors of ECCS'05 for making it possible for all the participants to share their enthusiasm and ideas in the most constructive way.

Paul Bourgine

François Képès Marc Schoenauer

\section{Fax +4161306 1234 E-Mail karger@karger.ch www.karger.com}

KARGER (c) 2006 S. Karger AG, Base 1424-8492/06/0033-0007 $\$ 23.50 / 0$ Accessible online at: www.karger.com/cpu 